\title{
Personal Freedom beyond Politics and Human Rights: Women, Religion and Freedom in the Arab World
}

\author{
Maysar Sarieddine $e^{1,2, *}$ \\ ${ }^{1}$ Professor of Psychology at The Lebanese American University, Beirut, Lebanon \\ ${ }^{2}$ Professor of Psychology at Phoenecia University, District of Zaharani, Lebanon \\ *Correspondence: The Inner Space, Beirut, Lebanon. E-mail: maysar@gmail.com
}

Received: January 3, 2018

Accepted: January 12, 2018 Online Published: January 23, 2018

doi:10.5430/sass.v5n1p31

URL: https://doi.org/10.5430/sass.v5n1p31

\begin{abstract}
This article explores the issue of what constitutes freedom for women living in the Arab world. Central to the concerns addressed in this article is the issue of religion as a cultural force that defines the perceived limits of freedom. Ultimately, the issue addressed in the paper will be how best to understand the ways Arab women perceive their freedom and constraints without attempting to speak for them, or imposing a Western definition of freedom on their situation. In order to do this, a theoretical framework provided by dialogical liberation theory and depth psychology will be recommended.
\end{abstract}

Keywords: women's liberation, Islam, liberation psychology, freedom, Arab Spring, human rights

\section{Introduction}

The question of what constitutes freedom is a highly charged issue that is often dependent on specific cultural contexts (Foucault, 1977). The issue of power is central to the analysis of perceptions of freedom, as Foucault (1977) notes in his study of the birth of punitive societies in Europe in the $18^{\text {th }}$ century. Using Foucault's framework, cultural context can determine what a specific group of people regard as freedoms and constrictions. In this way, there is no universal sense of freedom, just as there is no universal notion of right and wrong. Both categories depend on a highly specific cultural and ideological framework, and can shift between continents and cultures (Foucault, 1977). The question of freedom as it relates to Arab women is especially fraught (Agyar, 2014). The highly charged notion of what it means to be free in contemporary Western society may differ significantly from what constitutes freedom in Arab cultures with non-Western traditions (Al-Mahadin, 2015).

The role of religion as it relates to notions of freedom in Arab contexts is also highly fraught. Citizens of Arab countries - especially women - do not always agree what constitutes freedom. As Gayatri Spivak (1988) noted, oppressed minorities do not always regard outside intervention as a form of liberation. Spivak asserted that speakers, organizations and governments who attempt to intervene in the lives of oppressed minorities often end up asserting their power over such minorities, thus leading to a situation in which the minorities have not been given a voice. Moreover, Spivak argued that those who claimed to speak for the oppressed were highly Eurocentric and often masked more overtly political aims under humanitarian concern. The dangers of the ruling class of Europeans pretending to speak for an oppressed minority group, even when they have the best of intentions, can often undermine the cause of liberation that they are so careful to promote (Spivak, 1988). This study will follow Spivak's critique by taking into account the voices of Arab women, who are so often spoken for by Western authorities and commentators.

The argument over so-called 'women's liberation' in Arab contexts is yet another symptom of our late stage of globalized capitalism, as Fredric Jameson (2015) argues. After decolonization in the 1960s and 1970s, a contradiction arose between individual bourgeois liberation in the so-called developed world (for instance, the women's movement and sexual liberation) and the more collective efforts in the decolonized countries. While the developed world saw the emergence of a new emphasis on the individual, the decolonized countries saw the resurgence of nationalism (which by the 1970s had been dismissed as regressive and dangerous in Europe and the 
United States) as a force for liberation. However, the emancipatory efforts of the first world, such as the women's movement, began to take on the supposedly 'universal' qualities that colonialized peoples once experienced under European imperial dominance, where Christianity and capitalism were treated with the same reverence that bourgeois individualism carries today (Jameson, 2015). 'We are always surprised, in the United States, when women from other cultures repudiate American feminism, itself by now a fixture of American foreign policy, as a purely cultural matter and an intrinsic component of American imperialism and oppression,' writes Jameson (2015). 'It is a debate that suddenly revives and enflames all the older debates about modernity and historical progress.' But Jameson distinguishes the contradiction at the very heart of this debate as a 'dialectical' one, 'in which the newer cultures of revolt institute new cultural norms which, oppressive and hegemonic in their turn, themselves call forth the same kind of struggle as was waged against the older universals' (Jameson, 2015).

With the emergence of this contradiction rises the conflict to be analyzed in the present essay, namely, what constitutes human rights and women's freedom when the very notion of 'freedom' has taken on the odor of an oppressive universality? Arab women are often regarded as facing difficulties and lacking freedom in their home countries, either for political or religious reasons (Agyar, 2014; Melki \& Mallat, 2016). Efforts have been made by humanitarian organizations in Western Europe to explore different strategies for improving the lives of women in Arab cultures, who are deemed oppressed and constrained by Western standards (Al-Mahadin, 2015). For instance, FEMEN, a French-Ukranian feminist group, claimed to liberate Muslim women from what they saw as the patriarchal forces at the heart of Arab culture and the Muslim religion. However, the controversy elicited by FEMEN stems from contradictory definitions of freedom. Where members of FEMEN saw the hijab, for example, as an instance of patriarchal oppression, many Muslim women who argued against the organization saw their hijab as granting them a special kind of dignity. Al-Mahadin (2015) noted that FEMEN often appropriated the voices of Muslim women to advance an essentially Western campaign on non-Western populations. FEMEN's calls for liberation often amounted attacks on Muslim women's religious beliefs and culture, thus problematizing the easy binary notions of freedom and oppression used to promote the activities of groups like FEMEN (Al-Mahadin, 2015).

Though research has focused on the religious and political aspects of freedom for women in Arab cultures (Charrad \& Zarrugh, 2014; Khalil, 2014), there is a significant gap in the research regarding Arab women's perception of freedom. The identified gap in the literature is that it is not known what Arab women believe to be the largest factors contributing to, or limiting, their freedom. Additionally, there is a gap in the literature regarding how religion defines equality between men and women, and how this definition has changed throughout the last decade. To date, no study has investigated how women perceive the influence of religion on their quotidian existence and how it affects their basic human rights. While authors like Khalil (2014) have used sociological and political terms to investigate the changing nature of gender equality in Tunisia following the Arab spring revolution in 2011, there have yet to be any studies to take into account psychological and experiential factors for women living in Arab contexts. Additionally, while Melki and Mallat (2016) noted the existence of gender discrimination in industries such as journalism, their study does not acknowledge the individual experiences of women and how they define equality. It is important to further explore not only statistical and quantitative factors about the relation between women and freedom, but to take into account the perceptions and beliefs of the subjects of the study.

\subsection{Problem Statement}

The problem of freedom for women in the Arab world is multiform, complex and politically contested (Al-Mahadin, 2015; Melki \& Mallat, 2016). The very definition of what constitutes freedom has received significant attention and critique from writers in an Arab context. While some see in the discourse on freedom the imposition of certain cultural practices as a form of neo-colonialism (Al-Mahadin, 2015; Charrad \& Zarrugh, 2014; Spivak, 1988), others promote the ideas of the Enlightenment as a way to promote liberty and equality in Arab cultures (Melki \& Mallat, 2016). Famously, Gayatri Chakravorty Spivak contested the notion that subaltern subjects could speak through Western rationalist discourse (Spivak, 1988). This is a problem because it leaves no room for the native discourses of women in non-Western cultures. With this in mind, the problem to be addressed in this study is the paradox of what it means be a liberated or free woman in an Arabic cultural context, and the contradictions that Arab women face when they attempt to speak for themselves in a culture that is determined to speak for them. The present study will take into account the theoretical framework provided by dialogical liberation theory and depth psychology, which will provide an adequate theoretical edifice to promote dialogue between cultures and to liberate non-Western women from Western rationalist discourse (Watkins, 2003; Wolff, 1943). Current studies show that not only are perceptions of freedom not always easy to measure using Western standards, but also that the political revolts of 2011 have not necessarily increased equality in the Arab world, which makes the present study increasingly necessary (Agyar, 2014; Charrad \& Zarrugh, 2014; Khalil, 2014). 


\subsection{Theoretical Framework}

The purpose of this study is to explore how women in Arab cultures conceptualize their notion of personal freedom. At this stage in the research, the notion of freedom will be generally defined as the perception of personal agency (Watkins \& Shulman, 2008). The theories guiding this study are Watkins's liberation psychology and Carl Jung's depth psychology. Liberation psychology will help focus on the relational aspects of psychological formation, and depth psychology will help examine how unconscious forces help form personality dynamics. Three theories will be used to support the present research project: dialogical theory, liberation psychology, and depth psychology. Dialogical theory promotes the notion that dialogue is a distinguishing feature of human society, one that holds the promise of liberation, both personal and social (Watkins, 2003). Rather than a solitary practice, liberation should be seen as a dialogical project that involves the promotion of non-violent forms of communication (Watkins, 2003). The notion of dialogical theory is also intricately tied up with the field known as liberation psychology. Liberation psychology aims to transform the nature of the social system by increasing participation in practices that can promote economic, ecological and social justice (Watkins \& Shulman, 2008). Rather than focusing on the positivistic nature of the discipline of psychology, liberation psychology is based on practices that aim to ameliorate the oppressive relations that exist between peoples, cultures, and societies. Ultimately, liberation psychology aims to promote an egalitarian and dialogical discourse (Watkins \& Shulman, 2008).

Additionally, the present study will take into account depth psychology, as practiced by Carl Jung (1968) and outlined by Wolff (1943). Depth psychology examines the problems of personality dynamics, especially with regard to how they relate to unconscious forces. Wolff (1943) emphasized that one's own personality is the result of social and deep psychological forces, to which judgment of self, bodily movements, self-evaluation, mental disease, emotional factors and interpersonal skills are subject. One of the strengths of depth psychology, according to Wolff (1943), is that it is non-pathologizing, and it includes therapeutic traditions that are designed to cultivate the expression of personality, rather than simply analyze it. The imbalance that exists within individuals is a broad social and psychological problem, which depth psychology hopes to correct and ameliorate (Wolff, 1943).

According to Watkins (2002), these theories intersect by viewing the ego as a partial and prejudiced. Depth psychology promotes attitudes that focus on listening, humility and embracing vulnerability. For a phenomenological study such as the present work, the combination of depth psychology and liberation psychology will allow a diversity of voices to be heard. These methods are ideal for the non-Western nature of the study because the combination of depth and liberation psychology brackets the Western ego's desire to control, dominate and define according to a system of scientific classification (Watkins, 2002). The purpose of the present study is to think beyond the standard systems of knowledge that are used to dominate non-Western cultures (Foucault, 1977).

\section{Review of Relevant Literature}

\subsection{Human Rights and Islam}

It is easy to overlook the fact that before the doctrine of human rights was launched by Enlightenment thinkers in the West, Islam had it's own conception of the notion of human rights and freedom. The doctrine of human rights is generally concerned with protecting human beings from the power of a higher ruling authority, and in this sense human rights constitute freedom from some sort of hypothetical tyranny (Hashemi \& Qureshi, 2017). But as the West began to practice colonial rule, certain conceptions of rights and privileges were imported from countries like France and Great Britain. According to Hashemi and Qureshi (2017), some Muslim intellectuals and statesmen adopted the principles of European constitutionalism in the $19^{\text {th }}$ century, which lead to the acceptance of such principles and inaugurated a challenge posed to Islamic cultures. The strongest of these ideas came from French concepts that were born during the French Revolution, such as the notion of public liberty; conversely, modes of democratic freedom prevailed in areas of the Arab world dominated by the British. In the $19^{\text {th }}$ century many Muslim intellectuals disseminated democratic and human rights ideals. Such intellectuals were often educated in the colonial master countries, causing a trickle-down effect of ideas that filtered into and replaced much of Islamic doctrine (Hashemi \& Qureshi, 2017).

In 1973 the Charter of the Organization of the Islamic Conference (OIC) issued a charter affirming, but augmenting, their dedication to the UN charter on human rights. For instance, there was no provision in the OIC charter for equal rights for all persons regardless of sex or religion. While the language in the OIC charter puts much emphasis on the equal 'dignity' of men and women it does not mention anywhere that both sexes should maintain the same political and economic rights that the UN charter sets out, creating an extensive grey area which has been challenged by UN 
officials (Hashemi \& Qureshi, 2017). The charter also omitted provisions calling for the observance of democratic principles and guarantees of freedom of religion, association, freedom of the press and total equality under the law. Though so-called 'secular' Muslims have tried to open up the chasm erected by the OIC charter and to call for more overtly emancipatory legislation, more religious governments like Saudi Arabia have cracked down on protest (Hashemi \& Qureshi, 2017).

Though Hashemi and Qureshi (2017) also note that activist have difficulty looking to a Western model for human rights and emancipatory techniques, due to the widespread use of torture on behalf of the United States, as well as the emergence of detention centers like Guantanamo Bay. In the world after the terrorist attacks September 11, 2001, the notions of freedom, equality and justice have taken on a more elastic meaning.

\subsection{Islam and Perceptions of Freedom}

In order to better understand what constitutes freedom, it is important to dissect how women perceive their social roles in societies in which Islam is the dominant religion. While the question of freedom is important for the purposes of the current study, it is even more vital that current research takes into consideration how women who are immersed in such societies view their place within the social totality. Hence, the following section will review the literature on the role that religion plays in women's perceptions of freedom in the Arab world.

As Agyar (2014) demonstrates, issues concerning leisure play an important role in the perceived freedom of Turkish women. Life satisfaction can often be predicted according to a woman's leisure participation frequency, perceived leisure, and leisure satisfaction, according to the author. Using a sample of 1,437 female participants involved with recreational sporting activities, the researcher conducted a statistical analysis that showed that income and age were the largest determinants of life satisfaction in Turkish women. Ultimately, weekly leisure participation frequency did not have a large impact on life satisfaction, contrary to the assumptions of the researcher at the beginning of the study. Additionally, perceived freedom in leisure did not contribute significantly to life satisfaction. Agyar (2014) pointed to the problem in determining what scale or metric should be used to measure life satisfaction and perceptions of freedom for women in Arab cultural contexts. This study suggested that normal psychological social, and aesthetic subscales of leisure satisfaction are not always accurate tools for measuring happiness. This can be applied to the current study by emphasizing the difference between Western and non-Western discourses.

Similarly, Al-Mahadin (2015) has documented the contradiction at the heart of the issue of the perception of freedom. As noted in the introduction, the French-Ukrainian group FEMEN has come to embody the contentiousness that has built up around the issue of freedom for Arab women. Often, FEMEN's calls for liberation amounted to nothing more than an attack on Muslim women's religious beliefs and culture, thus problematizing the easy binary notions of freedom and oppression used to promote the activities of groups like FEMEN. Where some Muslim women saw the hijab as a emancipatory cultural item bound up with a certain concept of Muslim identity. Western groups like FEMEN denounce items like hijabs because they are deemed repressive.

\subsection{Islam, Freedom and Political Revolution}

Also key to the present discussion is the issue of politics. The question of emancipation is intimately bound to the notion of revolution. As revolution has been a recent development in the Arab world, with the Arab Spring of 2011, it is increasingly important to examine the notion of women's liberation in light of the political developments in Tunisia, Egypt and Libya.

Charrad \& Zarrugh (2014) took into account the changes wrought by the Arab Spring revolts of 2011 with regard to gender policy in the country of Tunisia, where the protests first erupted. The authors situated the discussion within a shift from 'politics from above' to a 'politics from below' model, meaning that more popular forces and organizations have begun to shift the discourse on gender policy, as opposed to elite groups. Drawing on the work of Jurgen Habermas, the authors argued that this shift has been facilitated by the emergence of a new public sphere and engaged civil society following the protests of 2011. Formerly, write the authors, the expansion of women's rights in Tunisia was done by means of policy changes or 'politics from above,' whereas after the rewriting of the constitution in 2011 such changes came from women's groups making demands upon the state. The emergence of women's voices as agents of change within the Tunisian political and legislative context marks a dramatic shift in the role that women play in determining their own fate. This is relevant to the present study because it contextualizes questions about what constitutes women's rights in Arab cultural contexts.

Similarly, Khalil (2014) examined the gender politics of the Tunisian revolution of January 2011, noting that within the arc of the revolutionary period - which the author dates between January and October 2011 - saw a radical change in Tunisia's gender politics. Whereas the prerevolutionary model was state-sponsored and centralized, the 
post-revolutionary model saw the decentralization of feminist activism, which was no longer located strictly within the state apparatus. Though, the author notes, this does not mean that women saw themselves are more liberated after the revolution. Due to a return to Third World nationalist discourse, which uses a male-centered political frame, women faced more marginalization from the post-revolutionary transitional committees, the transitional governments' mistrial positions and from the media. By using a series of interviews, the author shows that women's place within Tunisian society changed during the revolutionary period, but not necessarily for the better. This is relevant to the present study because it addresses questions about how to re-organize society in order to benefit Arab women.

The question of freedom of speech is also central to the present discussion. Melki \& Mallat (2016) examined the role of female journalists - and the very new possibility that women could enter the journalistic profession - in the context of the Arab Spring. Melki \& Mallat (2016) focused on the issue of female marginalization within an Arab work context. The profession in question is journalism, which the authors claim is a particularly difficult field for women working in Arab countries. The authors hypothesized that factors pertaining to gender discrimination, sexual harassment, and the lack of a legally and socially enabling environment function in tandem to systematically discourage and block women's entry into the field of news journalism. In addition, there are systematic practices designed to push women out of news journalism as well. Using a survey of 250 Lebanese, Arab and international female journalists working in Lebanon, as well as analysis of ownership documents and qualitative interviews with 26 female journalists, the authors found that structural, institutional and cultural obstacles that have faced women for centuries around the globe continue to operate with potent effects in Lebanon and the rest of the Arab world. This is relevant to the present study because it is an example of the dominance of Western standards of freedom.

\subsection{Islam, Human Rights, and Violence Against Women}

With regard to the discussion of human rights, Islam and women's perception of freedom, it is imperative to mention the violence perpetrated against women in Arab cultures. Violence against women, or the more general gender-based violence, is a persistent problem in the Middle East, as it occurs in various situations or contexts, exists in many forms and condoned by certain societal structures. Due to recent conflicts and uprisings, many scholars have investigated the use of physical, emotional, and sexual violence against women and children as a weapon of war and intimidation, whether in their original setting or after seeking refuge at another location. In addition to the common issues that one may expect—such as overcrowding, lack of access to basic needs and services, rising food prices, and increased competition for limited work opportunities - refugees, especially women and children, are vulnerable to sexual and gender-based violence (Anani, 2013). For example, one study showed that Syrian women and girls were at great risk for rape and sexual violence while residing in the areas affected by the conflict, and that after relocating to Lebanon, female refugees were subject to intimate partner violence, early marriage, and survival sex or prostitution (Anani, 2013). Usta et al. (2008) also found similar results in Lebanese women during the 2006 conflict between the Hezbollah and the State of Israel. Specifically, incidents of domestic violence reportedly increased during and after the Hezbollah crisis (Usta et al., 2008). The issue of gender-based violence in conflict areas is worsened by victims' unwillingness to report incidents of gender-based violence and reluctance to seek support because of shame and fear of bringing dishonor to their families (Anani, 2013; Usta et al., 2008). Violence in times of conflict is not limited to those individuals directly engaged in armed battle; rather, conflicts put women and children at greater risk of violence, especially in the form of rape and sexual abuse (Anani, 2013; Usta et al., 2008). Violence against women is not only prevalent at times of conflicts and crises. Researchers have also shown that pregnancy puts women at greater risk for domestic or spousal violence (Hammoury et al., 2009; Okour \& Badarneh, 2011). A study of pregnant women in a northern desert region in Jordan (Okour \& Badarneh, 2011) revealed that $40.9 \%(n=303)$ of women had at least one experience of intimate partner violence during their pregnancy. Among these women, physical violence was the most common form of violence they experienced during pregnancy, followed by psychological violence and sexual violence (Okour \& Badarneh, 2011). When compared against demographic information, the researchers determined that the women who were more likely to experience violence during pregnancy were those who resided in the city, had six or more pregnancies, had four or more female children, and were under pressure to bear a male child (Okour \& Badarneh, 2011). These results show that women whose husbands are more pressured to produce male heirs are more likely to experience violence during pregnancy. This reinforces the common perception that patriarchy contributes to men's propensity for violent behavior, as patriarchal societies give high regard or status to men who rear more male than female heirs.

\subsection{Violence Against Women and Western Intervention}

Similar to the discussion of FEMEN noted above (Al-Mahadin, 2015), there is a conflict regarding the role of 
Western intervention and women's liberation as it relates to the issue to be explored in the present study. Gender issues are central when it comes to violence against women, but organizations like the Lebanese KAFA (Enough) have managed to provide a platform to speak out against violence and in favor of a self-determined liberation platform. Members of KAFA are multi-disciplinary professionals and human rights activists who help, protect, and fight for the rights of women (KAFA, 2014). These members include doctors, who help women recover and maintain good mental, physical, and psychological health; social workers, who assist women in need of employment and dwelling; and lawyers and legal aides, who help women through legal cases, including divorce, annulment, and child custody battles. KAFA also aims to raise awareness about violence against women, women's rights, and gender equality by providing seminars and conferences to both men and women in the city, as well as in rural communities (KAFA, 2014). Another organization, Nasawiya, aims for the same goal by using social media to raise awareness and recruit supporters for gender equality.

In addition to helping female victims of intimate partner violence, KAFA also establishes programs that help and support other victims of oppressive violence, such as children and migrant domestic workers. Migrant domestic workers - a demographic mostly composed of women - started entering Lebanon in the 1970s, and have since grown to somewhere between 200,000 and 250,000 individuals in the country (KAFA, 2014). The Lebanese government, as well as most governments from where these individuals originate, including Nepal and Bangladesh, has weak regulations for the recruitment and processing of migrant domestic workers. As such, these individuals are vulnerable to abuse and violence at hands of private agencies and brokers. According to the study conducted by KAFA (2014), the recruitment process often violates several human rights of migrant workers. Specifically, these operations include human trafficking and forced labor, and recruitment agencies often use the migrant workers' desperation and lack of knowledge to their advantage by requiring them to pay enormous sums of money, giving them minimal support upon arrival in Lebanon, and not ensuring that they gain adequate and respectable employment (KAFA, 2014). As such, many migrant workers suffer several forms of abuse from their employers, including physical and emotional violence, economic deprivation, overwork, underpayment, and sexual assault (KAFA, 2014). Specifically, results of a survey of 100 migrant domestic workers showed that $77 \%$ worked at least 14 hours every day without any rest periods, $96 \%$ had their personal identification documents retained by their employer, $90 \%$ were prohibited from going out alone, $91 \%$ were denied the right to a day off from work, $50 \%$ were physically detained inside the house, and $43 \%$ were not allowed to contact their families (KAFA, 2014). Additionally, $50 \%$ of the respondents indicated that they were not paid regularly and $40 \%$ stated that their employers deducted the fees paid to the recruitment agency from their wages, which left them with approximately 3 months without pay (KAFA, 2014).

Another problem faced by migrant domestic workers is the indecent work conditions. Approximately $60 \%$ of the respondents indicated that they did not have their own private space for sleep and for keeping their possessions, and $32 \%$ indicated having been denied access to medical treatment, the right to take sick leave, and the right to a private life (KAFA, 2014). In order to put an end to this inhumane treatment of migrant domestic workers, KAFA is working for the support and protection of migrant domestic workers by informing them of their rights, providing legal, medical, and psychological support, and by picketing government to regulate the recruitment and employment of all migrant domestic workers, as well as the recruitment process and tactics of agencies within and outside of Lebanon.

Among the most significant contributions of KAFA to the feminist movement in Lebanon is the creation and proposal of a law for the protection of women from all forms of discrimination and abuse in both the private and public sphere. Specifically, in 2007, KAFA drafted a bill entitled, "The Law to Protect Women from Family Violence" and proposed it to Parliament for consideration. KAFA continually persuaded Parliament to read through and consider the bill until its subsequent passing in 2014. As proposed bills are read, debated, and revised by several parliamentary sub-committees prior to signing, the proposed bill by KAFA was significantly modified and amended before it reached its final form.

\section{Implications of Theories of Freedom and Liberation}

One approach to solving or overcoming the contradiction at the heart of the issue of women's perception of freedom in the Arab world is to be resolved is to use the theories outlined in the introduction to the present study, namely depth and dialogical liberation psychology (Jung, 1968; Watkins \& Shulman, 2008). Such approaches work well with what Paulo Freire called the 'pedagogy of the oppressed', which is the struggle for justice and equality within the education system (Mithra, 2014). According to Freire, traditional education can be perceived as a conditioning 
process. Students are taught the same concepts and lessons through the same techniques and methods used for generations before them; thus, each batch of students is generally similar to the ones before it. Friere also conceptualized education as an instrument of liberation, by allowing people to reflect on their actions and behaviors, to uncover their hidden reality, and to actively reject or accept what is told and taught (Freire, 1970; Mithra, 2014). As Freire was raised in a society characterized by a rigid hierarchical social structure, this theory on pedagogy aimed to uncover the hidden oppressive reality inherent in the educational system, as well as in other social structures. In this revolutionary pedagogy, students and persons are allowed to question and scrutinize the exploitative and oppressive authority that has been shaping the course of education, and subsequently radically change such structures towards more liberating methods through the process of conscientization (Mithra, 2014).

The active dialogic process through which critical consciousness is awakened is characterized by several values as described by Freire. First, dialog should be participatory, interactive, and cooperative such that students or participants are able to discuss openly (Mithra, 2014). Second, the dialog should be situated within the participants' thought and language such that they are able to comprehend ideas and relate these to their own contexts (Mithra, 2014). Third, the dialogue should be critical in that it encourages participants to engage in self-reflection and social reflection (Mithra, 2014). Fourth, the dialog should be democratic, i.e. each individual has equal speaking rights (Mithra, 2014). Fifth, interaction should be dialogic - individuals are allowed to respond to each other, with no one person talking too long (Mithra, 2014). Sixth, the critical dialogue should also be active and interactive, i.e. the inquiry should result in action where feasible, as the knowledge created should lead the individuals to gain adequate power for social reform (Mithra, 2014). Lastly, the critical dialog should be affective and include emotions ranging from humor, compassion, and indignation (Mithra, 2014).

The implications of applying liberation psychology and depth psychology to the study of emancipatory movements are vast. As is shown in the literature reviewed in the pervious section, there are few social movements - with the exception of KAFA - based on the voices and judgments of the women in question. A dialogic approach should be used in order better understand the issue of women's perception of freedom and human rights within a highly religious context. Dialogic approaches can help lead to social advocacy, as well as offer a fair and non-dominating relationship between the oppressor and the oppressed. Following Spivak (1988), it is important to keep in mind that social advocacy is a matter of making sure the subaltern is not being spoken for or misrepresented in order to further Western neo-colonial ends. By including women in the research for further studies in female emancipation in Arab societies, researchers will be able to bridge the gap that exits in the debate between human rights in the Arab world and in European nations.

\section{Conclusion and Recommendations}

In conclusion, I recommend that further phenomenological studies be conducted regarding the issues of what constitutes women's perceptions of freedom within the highly fraught human rights context of Arab and Islamic cultures. Only a phenomenological study can promote the notions of freedom that need to be articulated by the women who seek such freedom. A phenomenological approach will allow the researcher to take in the subjective experiences of women in Arab countries, rather than rely on quantifications and assessments that take into account the bias set by the research program itself. Phenomenology offers the advantage of focusing on individual subjective experiences, which aspires towards an analysis of everyday life and everyday lived experience that other studies, such as quantitative studies, cannot offer (Giorgi \& Giorgi, 2003). The aim of phenomenology is to capture an individual's subjective experience. This is opposed to ethnography or case studies, which seek to quantify or place onto a scientific metric a certain amount of objective numerical data collected in the field (Giorgi \& Giorgi, 2003).

While there are many voices in the debates regarding female emancipation in the Arab world (Al-Mahadin, 2015), it is important to recognize that the most importance voices are those of the women themselves, who should not be spoken for under the guise of a Eurocentric quantitative study. Thinkers like Jameson (2015) point out the inherent contradictions based on this debate, which I believe can be overcome by bypassing the Western, Eurocentric standards of emancipation inherited from Enlightenment discourse and giving a platform to the women who are the supposed target of this form of liberation.

\section{References}

Agyar, E. (2014). Contribution of perceived freedom and leisure satisfaction to life satisfaction in a sample of Turkish women. Social indicators research, 116(1), 1-15. https://doi.org/10.1016/j.sbspro.2013.10.153 
Al-Mahadin, S. (2015). Do muslim women need saving? Making (non) sense of FEMEN's ethico-aesthetics in the Arab world. Women's Studies in Communication, 38(4), 388-392. https://doi.org/10.1080/07491409/2015/1088289

Anani, G. (2013). Dimensions of gender-based violence against Syrian refugees in Lebanon. Forced Migration Review, 44(1), 75-78. Retrieved from http://www.fmreview.org/

Charrad, M. M., \& Zarrugh, A. (2014). Equal or complementary? Women in the new Tunisian constitution after the Arab spring. The Journal of North African Studies, 19(2), 230-243. https://doi.org/10.1080/13629387.2013.857276

Creswell, J. (1997). Research process methodologies and the doctoral process. New Directions for Higher Education, 99(3), 33-46. https://doi.org/10.1002/he.9903.

Douki, S., Nacef, F., Belhadj, A., Bouasker, A., and Ghachem, R. (2003). Violence against women in Arab and Islamic countries. Archive of women's health, 6(3), 165-171. https://doi.org/10.1007/s00737-003-0170-x

Drever, E. (1995). Using Semi-Structured Interviews in Small-Scale Research: A Teacher's Guide. Glasgow: SCRE Centre.

Foster, D. (2004). Liberation psychology. Self, Community and Psychology. Cape Town: UCT Press. 1-44.

Foucault, M. (1977). Discipline and Punish: The Birth of the Prison. New York: Pantheon.

Francis, J., Johnston, M., Robertson, C., Gildewell, L., Entwistle, V., Eccles, M., \& Grimshaw, J. (2010). What is an adequate sample size? Operationalizing data saturation for theory-based interview studies. Psychological Health, 25(10), 1229-1245. https://doi.org/10.1080/08870440903194015.

Freire, P. (1970). Pedagogy of the oppressed (M. Ramos, Trans.). New York, NY: Continuum. (Original work published 1970)

Giorgi, A. P., \& Giorgi, B. M. (2003). Chapter 13: The descriptive phenomenological psychological method. Qualitative research in psychology: Expanding perspectives in methodology and design, pp. 243- 273. Washington, DC: American Psychological Association.

Guest, G., Bunce, A., \& Johnson, L. (2006). How many interviews are enough? An experiment with data saturation and variability. Field Methods, 18(1), 59-82. https://doi.org/10.1177/152822X05279903

Hammoury, N., Khawaja, M., Mahfoud, Z., Afifi, R., \& Madi, H. (2009). Domestic violence against women during pregnancy: The case of Palestinian refugees attending an antenatal clinic in Lebanon. Journal of Women's Health, 18(3), 337-345. https://doi.org/10.1089/jwh.2007.0740

Hashemi, N., \& Quershi, E. (2017). Human rights. The Oxford Encyclopedia of the Islamic World. Retrieved from $\mathrm{http}: / / w w w . o x f o r d i s l a m i c s t u d i e s . c o m / p r i n t / o p r / t 236 / \mathrm{e} 0325$

Jameson, F. (2015). The aesthetics of singularity. New Left Review, (92), 101.

Jung, C. G. (1968). Analytical psychology: Its theory and practice. London, UK: Routledge.

KAFA. (2014). Dreams for sale: The exploitation of domestic workers from recruitment in Nepal and Bangladesh to working in Lebanon. Beirut, Lebanon: KAFA.

Khalil, A. (2014). Tunisia's women: Partners in revolution. The Journal of North African Studies, 19(2), 186-199. https://doi.org/10.1080/13629387.2013.870424

Melki, J. P., \& Mallat, S. E. (2016). Block her entry, keep her down and push her out: Gender discrimination and women journalists in the Arab world. Journalism Studies, 17(1), 57-79. https://doi.org/10.1080/14616670X.2014.962919

Mithra, H. G. (2014). Paulo Freire's educational theory and approach: A critique. Asia Journal of Theology, 28(1), 96-118. Retrieved from http://btessc.org/asia-journal-of-theology.php

Okour, A. M., \& Badarneh, R. (2011). Spousal violence against pregnant women from a Bedouin community in Jordan. Journal of Women's Health, 20(12), 1853-1859. doi:10.1089/jwh.2010.2588

Spivak, G. C. (1988). Can the subaltern speak? Marxism and the Interpretation of Culture. Macmillan: Basingstoke, 271-313. https://doi.org/10.1007/978-1-349-19059-1_20

Usta, J., Farver, J. M., \& Zein, L. (2008). Women, war, and violence: Surviving the experience. Journal of Women's Health, 17(5), 793-804. https://doi.org/10.1089/jwh.2007.0602 
Watkins, M. (2003). Dialogue, development, and liberation. Dialogicality in Development. Westport, CT: Greenwood, 87-109.

Watkins, M., \& Shulman, H. (2008). Towards psychologies of liberation. Basingstoke: Palgrave.\# https://doi.org/10.1057/9780230227736

Wolff, W. (1943). The expression of personality; experimental depth psychology. Oxford: Harper. 